\title{
SABERES DA BIODIVERSIDADE: PERSPECTIVAS DECOLONIAIS NO CURRÍCULO DO ENSINO DE BIOLOGIA
}

Marco Antonio Leandro Barzano ${ }^{1}$

André Carneiro Melo ${ }^{2}$

\section{CONTEXTUALIZANDO...}

A verdade, porém, é outra. Não importa em que sociedade estejamos, em que mundo nos encontremos, não é possível formar engenheiros ou pedreiros, físicos ou enfermeiras, dentistas ou torneiros, educadores ou mecânicos, agricultores ou filósofos, pecuaristas ou biólogos sem uma compreensão de nós mesmos enquanto seres históricos, políticos, sociais e culturais; sem uma compreensão de como a sociedade funciona. E isto o treinamento supostamente apenas técnico não dá. (Paulo Freire, 1992)

Nas primeiras décadas do século XXI temos visto aquilo que podemos considerar como potente no que diz respeito a outros modos de ensinar e aprender biologia e de compreender aquilo que se curriculariza no cotidiano das aulas dessa disciplina escolar. De uma certa maneira, essa potência apenas reforça aquilo que já desde a década de 80 do século XX vem apostando: uma visão menos tecnicista, naturalizada, biologizada, focada em bases cognitivistas, para se tornar de caráter mais social, cultural, econômico e ético.

De lá para cá, vários esforços têm sido experimentados, sobretudo a partir da criação de associações científicas, como a Associação Brasileira de Ensino de Biologia (SBEnBIO) e Associação Brasileira de Pesquisa em Educação em Ciências (ABRAPEC), ambas no ano de 1997, além do incremento de Programas voltados à Educação em Ciências, e na área de Educação, que possui linhas/grupos de pesquisas voltados à educação em ciências.

\footnotetext{
1 Doutor em Educação pela Universidade Estadual de Campinas (UNICAMP). Professor Titular da Universidade Estadual de Feira de Santana. E-mail: marco.barzano@ gmail.com https://orcid.org/0000-0003-3273-9216

${ }^{2}$ Doutor em Ensino, Filosofia e História das Ciências pela Universidade Federal da Bahia/ Universidade Estadual de Feira de Santana. Pesquisador do RIZOMA/UEFS. E-mail: acmbio@ yahoo.com.br https://orcid.org/0000-0003-1974-0052
} 
Nesse mesmo período, houve um maior acesso e investimento aos meios de comunicação tecnológicos; ao avanço da biotecnologia e a emergência de temas de cunho mais intensamente sociocultural, quais sejam: relações étnico-raciais (etnia, racismo, identidades); gênero e sexualidade (identidades, feminismo, homofobia, pedagogia queer); meio ambiente (agrotóxicos, transgênicos; agroecologia, sustentabilidade), entre outros, que faz com que o ensino de biologia possa ser mais criativo, que permite compreender nosso papel no mundo, a partir ideias mais humanizadas, de solidariedade, empatia, da diversidade, inclusão e ética, que respeita a diferença, em resumo: que seja um ensino de biologia que consegue descolonizar saberes.

É possível afirmar que a virada do século é também uma virada epistemológica no campo das ciências humanas, da educação e, em especial, do ensino de biologia, que emerge com novas produções de conhecimento; de protagonismo dos (novos) movimentos sociais com suas conquistas de visibilidade e a promoção de novos saberes e conhecimentos ora silenciados, mas sempre em processo de luta e resistência.

A partir desse breve contexto, consideramos importante destacar que, nesse mesmo período entre o final do século XX e início do século XXI, há o que consideramos de retrocesso no que se refere ao "mundo globalizado" apontando como uma de suas consequências, a estandardização dos exames de larga escala, além dos documentos curriculares oficiais, como a BNCC, por exemplo, que consideramos como uma "perversidade curricular", pois além de retroceder para focar em aspectos meramente técnicos, acríticos, descontextualizados, ou seja, tudo aquilo que contestamos, refutamos e que, na contemporaneidade, aparece como algo solucionador para os atuais problemas da educação brasileira.

No presente artigo, apresentamos uma reflexão teórica sobre a tríade currículo-relações étnico-raciais e educação ambiental, a partir de uma revisão bibliográfica constituída de artigos, livros, dissertações e teses e, além disso, trazemos o recorte de uma pesquisa de tese de doutorado (MELO, 2019) desenvolvida pelo grupo de pesquisa RIZOMA e que foi pautada naquilo que denominamos de "currículo das margens" (BARZANO, 2016) quando se refere "às temáticas/conteúdos que atravessam os currículos dos cursos de Licenciatura e afetam o cotidiano escolar, bem como dos sujeitos que são produzidos por estes currículos tanto nos cursos de Licenciatura quanto na escola" (p. 105).

A tese teve como objetivo identificar e valorizar outros modos de pensar e estar no mundo, e levou em consideração o espaço de possibilidades que dinamizam a ligação dos seres humanos em processos simbióticos com a biodiversidade, assinalando o significado e as formas que o ensino de 
ciências/biologia pode assumir no contexto da singularidade territorial quilombola. Além disso, destacamos que os resultados dessa pesquisa têm contribuído para a descolonização dos currículos (GOMES, 2012), principalmente os do ensino de biologia, envolvendo professores(as) e pesquisadores(as) envolvidos(as) com a formação de professores(as) para a atuação na educação básica e que devem estar implicados(as) com o compromisso de que o currículo escolar contemple discussões acerca das relações étnico-raciais justas, conforme é recomendado por Verrangia (2012).

Este mesmo autor enfatiza a importância de se discutir e superar a visão biológica de raças humanas, tão necessária ainda nos dias atuais e, para isso, ele cita, por exemplo, que: “é importante compreender as relações entre os conhecimentos científicos e a orientação das relações étnicoraciais desiguais, como o papel das teorias raciais do século XVIII e XIX e a fundamentação do chamado "racismo científico" (VERRANGIA, 2012, p. 07).

Além disso, apontamos no texto que essa pesquisa, que aborda sobre os saberes da biodiversidade em uma comunidade quilombola, se relaciona com a proposta de Gomes (2017) a partir de uma "desobediência epistêmica", quando nos mostra que o movimento negro é educador e, dessa maneira, há uma efetiva contribuição para descolonizar os currículos e dar visibilidade às vivências e práticas pedagógicas.

Instigados pelos questionamentos de Gomes (2012), sobre pesquisas relacionadas às relações étnico-raciais e descolonização dos currículos, a autora pergunta: novas indagações ou um novo contexto? Outro paradigma epistemológico? Isso nos provoca e permite-nos argumentar neste artigo que nos últimos anos, sobretudo no que se refere aos últimos dez anos, o curso de Licenciatura em Ciências Biológicas tem promovido pensar um currículo capaz de criar possibilidades de conhecer outras visões de mundo, com centralidade nas culturas e diversidades (HALL, 1997; SILVA, 1999; MACEDO, 2004, 2006, 2007 2009; MOREIRA; CANDAU, 2008; 2014; PARAÍSO, 2009, 2010) e conforme tem sido apontado nas investigações de Fernandes (2015; 2018); Sepulveda et al (2019); Dias et al (2018); Verrangia e Silva (2010); Verrangia (2012); Verrangia e Castro (2014); Pinheiro e Rosa (2018), entre outros(as) que abordam sobre o ensino de ciências e biologia e a educação em ciências decolonial para a promoção antirracista nos currículos da educação básica ou do nível superior.

Torna-se imperativo destacar que o currículo produz sujeitos e, dessa maneira, defendemos que a discussão acerca das relações étnico-raciais, sobretudo a partir da lei 10.639/03, não está circunscrita ao ensino de História, como muitas vezes é comentado no cotidiano das escolas e até mesmo dentre os(as)pesquisadores(as) da educação em ciências. Ao contrário, essa lei já foi 
instituída há mais de quinze anos e o debate sobre ela já circula em um expressivo número de artigos, dissertações e teses no campo educacional e das ciências humanas e sociais, e tal discussão tem sido disseminada em vários congressos e eventos em que circulam pesquisadores(as) e professores(as) da educação básica, em suas formações continuadas.

Desse modo, concordamos com Verrangia (2012) quando diz: "não há porque o docente de Ciências sentir-se inseguro quanto a tomar seu papel nessa empreitada e envolver-se com atividades e projetos ligados ao combate ao racismo e às discriminações” (p. 06).

O artigo discute a tríade temática: "currículo, relações étnico-raciais e educação ambiental”, pois além de fazer parte de nossos interesses investigativos, são temas que consideramos importantes na formação do(a) professor(a) de biologia, com a intenção de contribuir para somar e fortalecer a discussão e criarmos possibilidades para que seja construída uma pedagogia decolonial e de compreensão da centralidade étnico-racial e ambiental que é atravessada pelo currículo. A análise empreendida se baseou nos conceitos de sociologia das ausências e sociologia das emergências, desenvolvidos por Santos (2007) e ampliados por Gomes (2003; 2012; 2017).

Encerramos essa Introdução conclamando Paulo Freire, resistindo e apostando na insubordinação necessária da ruptura da biologia que até pouco tempo não contemplava o debate sociocultural, tão importante para a compreensão de mundo e formação cidadã e de justiça social.

A defesa que apresentamos no presente artigo está em consonância com a proposta de Santos (2005) por uma universidade para o século XXI emancipatória que tem entre algumas diretrizes: a de valorizar a formação inicial e sua articulação com os programas de formação continuada; a reestruturação dos cursos de Licenciatura, de forma a assegurar a integração curricular entre a formação profissional e acadêmica; a colaboração entre universidade-escola pública para difusão do saber pedagógico (SANTOS, 2005).

\section{O CURRÍCULO DE BIOLOGIA E A CENTRALIDADE NAS CULTURAS}

Ao apresentar sobre a virada cultural, Hall (1997) nos mostra em seu clássico artigo "A centralidade da Cultura - notas sobre as culturais do nosso tempo", que a cultura é central e perpassa tudo o que ocorre em nossas vidas, bem como daquilo que representa o que fazemos. Nos últimos anos, sobretudo no campo da Educação contemporânea, ela tem sido posta como categoria analítica, principalmente a partir do final da década de 1990, em um número significativo de investigações e isso não tem deixado de ocorrer no campo da Educação Ambiental. 
No ensino de biologia isso não foi diferente, mas apareceu um pouco mais tarde, em meados dos anos 2000, principalmente, nos trabalhos investigativos do campo do currículo, apresentados, em sua maior parte, a partir da colaboração de Silva (1999) que, além dos resultados de suas pesquisas, foi tradutor de várias obras em que os estudos culturais foram contemplados. Tais produções foram importantes para os campos de interlocução da Educação Ambiental e Ensino de Biologia.

Em um artigo anterior (BARZANO, 2016, 116) mencionamos que "há determinados sujeitos e temas que merecem maiores investigações, quais sejam: comunidades tradicionais; escolas do MST; escolas família agrícola; agroecologia; agrotóxicos; transgênicos etc.” tanto na educação ambiental quanto no ensino de Biologia. Nosso argumento é de que para esse público há uma necessidade de que os conteúdos/temas sejam abordados do ponto de vista das culturas, e não somente pelo viés da teoria crítica, marcada sobretudo nas décadas de 1980-90.

Ao defendermos a centralidade da cultura no currículo de biologia, buscamos apoio em dois textos que tratam sobre cultura no ensino de biologia e que apresentamos para dialogar neste artigo, quais sejam: "currículo e cultura: diálogos com as disciplinas escolares Ciências e Biologia" (FERREIRA, 2014) e "Planejamento de ensino, cultura e Biologia" (GOMES, 2016). O primeiro deles tem a centralidade no currículo das disciplinas de Ciências e Biologia e a autora constrói seu argumento procurando compreender como os discursos dessas duas disciplinas operam atualmente com a questão cultural e, para isso, ela recorreu aos trabalhos apresentados no IV Encontro Nacional de Ensino de Biologia em 2012 e que foram publicados na Revista da SBEnBIO. ${ }^{3}$

A partir do exame de vinte trabalhos encaminhados para o eixo temático nomeado "Relações entre educação, ciências e culturas", a autora buscou indícios que permitiram-na "entender como as relações entre currículo e cultura estão sendo discursivamente produzidas no ensino de Ciências e Biologia e, simultaneamente, na formação de professores da área” (FERREIRA, 2014, p. 199) e uma de suas conclusões foi de que "os conhecimentos escolares são elaborados a partir da associação de critérios diversos, alguns advindos de uma noção culturalista de currículo e outros de tradições curriculares que vieram, sócio-historicamente, definindo o que é e o que não é científico" (p. 205).

O texto de Gomes (2016) teve o objetivo de refletir sobre as "práticas de planejamento de ensino em meio ao debate sobre a cultura nos currículos escolares de Biologia” (p. 35) a partir da inspiração em Stuart Hall e revelou que "ao observar as tensões provocadas pelos debates sobre a

\footnotetext{
${ }^{3}$ www.sbenbio.org.br
} 
cultura no ensino de Ciências e Biologia busco compreender os sentidos do que está de fato acontecendo com essas disciplinas escolares em meio a todas as demandas culturais que vêm se impondo nos contextos escolares" (p. 36).

Para que a autora pudesse tecer suas considerações, ela tomou a parte da Apresentação de três artefatos: os Anais dos três primeiros Encontros Regionais do Ensino de Biologia da Regional $2^{4}$ da SBEnBIO, pois, segundo ela, tais materiais são exemplos de "como as questões relativas ao conhecimento e suas relações com aspectos da cultura vêm acompanhando as nossas preocupações sobre como enfrentar as problemáticas relativas ao ensino das disciplinas Ciências e Biologia" (GOMES, 2016, p. 37).

A partir dos dois textos supracitados, defendemos neste artigo que a SBEnBIO, como comunidade disciplinar, foi (tem sido), desde 1997, propulsora para a pluralidade de temas e abordagens que contemplam o aspecto cultural, tendo em vista que, desde seu primeiro encontro nacional, apresentou um eixo temático específico: "relações entre educação, ciências e culturas" (grifo nosso), de modo mais explícito com o termo cultura, que ainda apareceu no plural, como consideramos que seja o mais apropriado na contemporaneidade.

$\mathrm{Na}$ próxima seção, apresentaremos o relato de uma pesquisa que é um amálgama entre educação ambiental e relações étnico-raciais. A investigação tem inspiração na ecologia de saberes (SANTOS, 2002) e perspectiva decolonial de Mignolo (2008); Arboleda (2011) e Gomes (2012; 2017).

\section{CURRÍCULO-EDUCAÇÃO AMBIENTAL-RELAÇÕES ÉTNICO-RACIAIS: INTERLOCUÇÕES}

A partir de uma reflexão teórica e epistemológica, focamos nosso interesse de pesquisa sobre os saberes da biodiversidade ou dito de outra maneira: da "vida em diversidade" e como esses saberes são subalternizados, subjugados e submetidos ao poder da objetivação da ciência moderna. O trabalho de construção de uma nova racionalidade, proposto por Santos (2002), é fundamentado em três premissas: a experiência social em todo o mundo é muito mais ampla e variada do que a tradição científica conhece e considera importante; esta riqueza de experiência está a ser desperdiçada e para se combater o desperdício dessas experiências faz-se necessário propor um modelo diferente de racionalidade.

\footnotetext{
${ }^{4}$ Regional que contempla os estados do Rio de Janeiro e Espírito Santo.
} 
A partir disso, buscamos apostar em uma perspectiva conceitual de biodiversidade que fosse para além do seu conceito biológico, do conceito já estabelecido pelo logos científico da modernidade e muito comum nos cursos de Licenciatura em Ciências Biológicas, sobretudo na formação inicial de futuros(as) professores(as) de ciências e biologia da educação básica.

A pesquisa, portanto, abordou essas questões a partir da perspectiva de Santos (2005), focada na análise de suas configurações que incluem e privilegiam os saberes tradicionais sobre a biodiversidade. Nesta investigação empreendida argumentamos que a biodiversidade não se encerra em um conhecimento da biologia ou da ecologia; não se trata apenas do saber a respeito da riqueza dos seres vivos, das suas relações e dos seus habitats, mas também e, principalmente, da construção de sentidos coletivos e identidades compartilhadas com significações culturais diversas.

A partir das leituras dos referenciais decoloniais, o grupo de pesquisa RIZOMA apostou em priorizar o enfoque em uma investigação que trata sobre biodiversidades e comunidades quilombolas, num "giro decolonial" e buscamos propostas metodológicas que permitam articular referências de ensino de ciências e biologia com o da decolonialidade e que, desta forma, procura responder às lógicas da colonialidade, apostando em outras experiências, vivências e produção de conhecimentos subalternizados, tornados inexistentes a partir da racionalidade hegemônica.

É evidente que o conhecimento proveniente dessa racionalidade e a diversidade de saberes e experiências presentes nos conhecimentos tradicionais, são apresentadas como dimensões antagônicas, mas, por outro lado, o presente artigo faz questão de sublinhar o quanto o ensino de ciências/biologia e as questões de culturas parecem ter sido sempre apartadas pela hegemonia do pensamento dominante e assim nos provoca a refletir sobre as formas de articulação de saberes que convivem no espaço/tempo da escola e, dessa maneira, descolonizar os currículos, sobretudo daqueles(as) que fazem parte do cotidiano das escolas em comunidades quilombolas, com suas singularidades e que almejam romper com o currículo prescritivo e monocultural, eurocentrado e passa a promover um currículo intercultural e decolonial, com lugar para a diversidade nos discursos e práticas curriculares (GOMES, 2012).

A reflexão pretendida aqui a esta lógica da colonialidade é abrir espaço para pensar sobre os conhecimentos subjugados e valorizá-los com base no diálogo entre diferentes saberes, diferentes culturas, no reconhecimento da diferença e do direito da diferença. Desse modo, "a descolonização do currículo implica conflito, negociações e produz algo novo” (GOMES, 2012, p. 107).

\footnotetext{
5 O giro decolonial se caracteriza por um movimento teórico, ético, político e epistemológico que questiona as pretensões objetivas do conhecimento científico (CASTRO-GÓMEZ \& GROSFOGUEL, 2007).
} 
A forma singular de apropriação da natureza por parte de comunidades tradicionais cria uma identidade dessa população, pois ela é, muitas vezes, construída a partir de processos simbióticos com a biodiversidade, pautados nas relações cotidianas de trabalho com a terra, no conhecimento tradicional associado às práticas produtivas, aos modos de pensar e estar no mundo.

Consideramos que ao realizarmos pesquisas em territórios quilombolas contemporâneos é, antes de tudo, ter a possibilidade de entrar em contato com energias ancestrais. Uma ancestralidade revelada na elaboração de saberes que se organizam nas diversas formas de vida e de resistência dessas comunidades, expressas na sua relação com os elementos da natureza, com a terra como um ente gerador de força vital e os frutos dessa relação não só com a terra, mas também com a água, com a mata, isto é, com os seus territórios e a sua biodiversidade.

Essas comunidades imaginam coletivamente os exercícios de resistência às formas coloniais de apagamento, na linha do que Arboleda (2011), teórico colombiano dos estudos culturais, define como "suficiências íntimas" (p.11). Essa categoria se refere a saberes e fazeres necessários para garantir a autonomia das comunidades locais, inscritos em sabedorias compartilhadas pelos grupos sociais em projetos comunitários históricos que orientam ações coletivas no sentido de auxiliar na conservação da vida e permite compreender que é possível pensar o patrimônio e, sobretudo a sua gestão, a partir da autonomia e da repolitização da memória.

Essa estreita relação dos povos tradicionais com elementos da natureza, configurada como respeitosa, orgânica e simbiótica com todos os elementos vitais se caracteriza como uma das principais chaves para compreensão de questões que interessam essa investigação.

É importante ressaltar, teórica e metodologicamente, que a imersão nesses territórios requer respeito e compreensão da sua realidade, pois a relação com o ambiente que os cercam, o manejo dos recursos naturais, são estratégias importantes na manutenção e reprodução da comunidade ao longo de suas gerações e, por isso, partimos, do pressuposto de que a vida em diversidade, conforme descrita anteriormente, é resultado da relação simbiótica entre natureza e culturas humanas, ao reconhecer a identidade dos povos tradicionais e os seus saberes como representações culturais de apropriação do patrimônio natural e o sentimento de pertença que essas comunidades desenvolvem em processos simbióticos com a biodiversidade e nas relações sociais cotidianas (LEFF, 2012). 


\section{EDUCAÇÃO QUILOMBOLA E ENSINO DE CIÊNCIAS/BIOLOGIA: CENÁRIOS, FISSURAS E TEIAS}

A educação quilombola define-se como parte de um todo estruturado em que emergem histórias, culturas e saberes da tradição quilombola. Para garantir aos estudantes o acesso aos conhecimentos por meio das ciências naturais é necessária a adoção de práticas pedagógicas que provoquem rupturas no modus operandi da ciência enquanto verdade absoluta. Esta modalidade de ensino surge como uma nova forma de pensar conteúdos escolares a partir da percepção que eles não podem ser compreendidos como receitas a serem ministrados em doses, frações, horários, mas revelar a condição de aprendizagem e ser elaborados a partir da real necessidade dos estudantes de tal forma que ao estudar os conteúdos se sintam participantes do processo de aprendizagem, pois estes são "saberes didatizados ou discursos recontextualizados” (LOPES; MACEDO, 2011, p. 108).

Neste sentido, a Educação Escolar Quilombola reivindica uma mudança de paradigma que requer a emergência de uma nova postura na formação de professores(as) preocupados(as) com o intercâmbio entre os saberes pedagógicos e os saberes da tradição quilombola em consonância com os conteúdos do ensino de ciências e biologia.

Freire (2014) aponta os caminhos para o rompimento e emergência desse novo paradigma: a dialogicidade, a troca de experiências, o encontro, o olhar emocionado. Partindo dessa perspectiva, os estudantes mudarão o percurso em um movimento carregado de significados, numa articulação de saberes que contam suas histórias, manifestam suas emoções, problematiza a realidade vivenciada no desejo de conhecer-se a si mesmo, recuperando conhecimentos antes silenciados por uma história deserdada de verdades sobre a trajetória dos povos africanos trazidos para o Brasil.

Para Trindade (2016):

[...] histórias estas que a educação brasileira se encarregou de reproduzir por mais de 400 (quatrocentos anos), de forma romântica e descontextualizada na perspectiva de contribuir para o embranquecimento, a exclusão e a separação entre negros, brancos e indígenas (p. 60).

A autora reforça que "estas histórias trazem consigo conhecimentos da matemática, das ciências naturais, da cultura que estão latentes nos marcos civilizatórios (p. 61)" e que pelo fato de serem componentes da diáspora africana trouxeram significativas contribuições genéticas e culturais para a formação do povo brasileiro.

A Lei n. ${ }^{\circ}$ 10.639/03 é, no âmbito das políticas públicas para promoção de igualdade racial, uma das primeiras e mais significativas medidas efetivas para reparar uma série de distorções 
contidas na educação brasileira. O ato de tornar obrigatório o ensino de História e Cultura Africana e Afro-Brasileira aos alunos e alunas brasileiros(as) é um marco seguido por uma série de medidas que incluem, dentre outros tópicos, a implementação de escolas em comunidades quilombolas que, em tese, deveriam conter conteúdos programáticos condizentes com a cultura local e total adequação às especificidades desses contextos.

Consideramos que, aos poucos, tem havido um avanço no que diz respeito à descolonização do currículo em escolas, nos cursos de Licenciatura em Ciências Biológicas, pois o currículo já se encontra bem diferenciado, como pode ser constatado no trabalho expositivo "Ciência, Raça e Literatura", desenvolvido em uma atividade que emergiu no componente curricular de Estágio Supervisionado em Ensino de Biologia, na Universidade Estadual de Feira de Santana, conforme foi relatado por Dias et all (2014) com realização das exposições itinerantes em universidades, museus e escolas, colaborando significativamente para o debate do racismo, do racismo científico, eugenia, gênero e raça, entre outros, e que tem culminado em uma proposição curricular decolonial e relacionada aos direitos humanos, conforme foi proposto por Sepúlveda (2018) e Sepúlveda et all (2019).

Na ecologia de saberes, cruzam-se conhecimentos e ignorâncias; e a ignorância não é necessariamente um ponto de partida, mas pode ser o de chegada para conhecimentos que são desaprendidos ou esquecidos, como é o caso dos saberes de comunidades locais que desenvolvem formas de se relacionar com a natureza/cultura (SANTOS; MENEZES, 2010).

Sobre esse aspecto, Tristão (2014) nos diz que:

[...] o gosto e o encanto que essas comunidades desenvolvem no trato de suas culturas em processos simbióticos com a natureza, nas relações sociais sonhadas da vida em comunidade, nas redes de solidariedade que tecem em seus cotidianos, nos afazeres sustentáveis que inventam a caça da sobrevivência diária, enfim, tudo isso nos coloca em condições de eternos aprendizes (p. 482).

As experiências e as vivências dessas comunidades e seus interesses cotidianos entram em cena no espaço escolar em um processo de negociação cultural que visa o fortalecimento desses novos saberes nos “entre-lugares” das propostas e práticas curriculares hegemônicas.

Essa negociação/disputa acaba potencializando a elaboração de um currículo que valorize outros modos de conhecer o mundo, e, portanto, que valorizem no currículo as diferenças culturais. Com isso, as práticas pedagógicas nas escolas quilombolas devem possibilitar a essas populações uma educação apropriada às suas diferenças étnicas e culturais: um currículo que contemple o 
contexto cultural em que as escolas estão inseridas e, desse modo, que escapem de práticas curriculares homogeneizadoras, hegemonicamente monocultural, eurocêntrico e de discursos conservadores, tão comuns em documentos curriculares governamentais e que recentemente têm sido (im)postos pela BNCC, por exemplo.

Tendo em vista que o documento que trata das diretrizes curriculares nacionais para a educação escolar quilombola (BRASIL, 2012) seja recente, é imperativo que haja um incremento de pesquisas que tenham o currículo da educação quilombola como objeto de estudo, sobretudo na área da educação em ciências, em especial no ensino de Biologia e, desse modo, deve-se instituir orientações para que os sistemas de ensino formulem projetos político-pedagógicos adequados à especificidade das vivências, realidades e história das comunidades quilombolas do país.

Tratando das identidades étnico-raciais, seu processo de construção é baseado na luta dos povos quilombolas, que envolve suas memórias, sua ancestralidade e seus conhecimentos tradicionais; também está ligado ao histórico de resistência que varia de acordo com as especificidades de cada comunidade.

A identidade assume um papel preponderante, pois é ela quem define o direito à terra, à demarcação do território e às políticas públicas, por isso, um novo pensamento curricular no âmbito da escola, é antes de tudo, uma identidade política. Diante disso, é necessário que se construa uma proposta curricular que articule identidade e cultura quilombola no interior da escola, promovendo a formação crítica, reflexiva e emancipatória dos estudantes quilombolas (MACÊDO, 2015).

É necessário, porém, argumentar que a construção desse currículo perpassa pelos instrumentos de luta, embates e enfrentamentos dos desafios ligados às demarcações dos territórios quilombolas, a conservação do meio ambiente, ao respeito ao modo de ser, estar e dialogar com o mundo. Esses processos de articulação entre a identidade e a cultura quilombola apontam quais caminhos o ensino de Biologia, que muitas vezes invisibiliza ou subalterniza outras formas de conhecimento, podem seguir na construção de uma ecologia de saberes. Ou seja, o que está se argumentando é que é necessário superar a abordagem de um currículo prescritivo, ainda vigente em muitas escolas, monocultural, marcado por uma epistemologia da ciência moderna.

Ao considerar que a ciência não reconhece como saberes válidos as tradições e experiências que homens e mulheres constroem a partir da relação com os lugares, com o meio onde tradicionalmente vivem, é possível compreender a razão pela qual o Ensino de Biologia sempre teve a lógica epistemológica dominante como referência no processo de seleção de saberes legítimos, servindo como ferramenta de "modernização" da cultura. 
A experiência social quilombola constitui-se de saberes nascidos da luta, produtora de relações sociais que forjam memórias duradouras e, ao mesmo tempo, renovadas a cada momento que é acessada; o ato de buscar as memórias significa fortalecer e ressignificar ensinamentos acerca de si mesmo que são fundamentais em um processo de reinvindicação contemporânea cuja a autodefinição quilombola é o ponto de partida (NUNES, 2014). Estes saberes tão imprescindíveis não apenas em processos educativos não-formais, mas no deslocar-se destes saberes do cotidiano para junto de outros saberes que fazem parte do repertório do espaço escolar.

Para esta mesma autora, a escola quilombola não pode ser apenas uma referência geográfica em um território negro; ela necessita tornar-se um espaço convidativo que redimensione os usos dos saberes tradicionais que foram submetidos à lógica epistemológica dominante.

Dessa forma, o currículo, no contexto da educação escolar quilombola, deve dialogar com os saberes da comunidade, levando em consideração os seguintes elementos: a memória coletiva; as línguas reminiscentes; as práticas culturais; as tecnologias e formas de produção do trabalho; os acervos e repertórios orais; os festejos, usos, tradições e demais elementos que conformam o patrimônio cultural das comunidades quilombolas e a sua territorialidade. São incontáveis as experiências sob a forma de saberes que se encontram nas comunidades quilombolas, elas, pode se afirmar, com todas as letras, geram a vida!

\section{CONSIDERAÇÕES FINAIS}

Exu nas escolas

Exu nas escolas

Exu nas escolas

Exu nas escolas

Exu no recreio não é Xou da Xuxa

Exu brasileiro

Exu nas escolas

Exu nigeriano

Exu nas escolas(...)

Estou vivendo como um mero mortal profissional

Percebendo que às vezes não dá pra ser didático

Tendo que quebrar o tabu e os costumes frágeis das crenças limitantes

Mesmo pisando firme em chão de giz

De dentro pra fora da escola é fácil aderir a uma ética e uma ótica

Presa em uma enciclopédia de ilusões bem selecionadas

E contadas só por quem vence

(Kiko Dinucci / Edgar Pererê)6

\footnotetext{
${ }^{6}$ Canção “Exu nas Escolas”. Elza Soares. Album: “Deus é mulher”, 2018.
} 
O artigo buscou apresentar o recorte de uma pesquisa que tem a centralidade na tríade temática: "currículo, relações étnico-raciais e educação ambiental", temas que consideramos emergentes e ainda invisibilizados na formação do(a) professor(a) de biologia, sobretudo no que se refere à educação quilombola. Apresentamos, a partir da perspectiva da descolonização dos currículos, uma reflexão e proposição acerca dos saberes da biodiversidade em uma comunidade quilombola, procurando defender a a potência do movimento negro educador e, dessa maneira, buscou formular uma contribuição para descolonizar os currículos de ciências/biologia e construir possibilidades para a insurgência de uma pedagogia decolonial.

Fernandes (2018, p. 95), ao falar sobre aquilo que denominou "biologia decolonial", nos provoca: "É possível construir outra educação das relações étnico-raciais partindo de outra biologia?”. A autora compreende que para responder essa provocação é necessário assumir uma postura de desobediência diante de um currículo que invisibiliza outras epistemologias e formas de produção de conhecimentos. É neste contexto que, corroborando com a autora, apontamos caminhos insubordinados, atalhos indisciplinados e trilhas insurgentes para se pensar o ensino de biologia não somente do ponto de vista biológico, mas, sobretudo de uma perspectiva biocultural.

Neste giro enunciativo foi possível desvelar saberes que se organizam nos modos de vida e de resistência das comunidades quilombolas, expressos nas formas de saber/fazer/pensar/sentir a biodiversidade (vida em diversidade) presente nos discursos e nas práticas cotidianas da relação com a terra, com o rio e com a caatinga. Ao refletir sobre seus saberes, os/as sujeitos/as quilombolas reviveram suas experiências e procuraram ressignificar os fragmentos das suas memórias bioculturais.

Essas memórias, ao serem ressignificadas, refletiram a relação de caráter simbiótico existente nas interações entre a cultura e os elementos da biodiversidade. Sendo assim, a construção de uma política específica de educação que contemple as especificidades socioculturais, étnicas e econômicas da comunidade é uma maneira de reconhecer e compensar, no âmbito educacional, o absoluto ocultamento e a invisibilidade histórica imposta às escolas pelo sistema oficial de ensino.

A epígrafe que abre as considerações finais deste artigo e que é entoada pela negra e mulher Elza Soares, anuncia os caminhos que se abrem e circulam enviando mensagens, como é próprio do orixá Exu e que Rufino (2019), em sua obra Pedagogia das Encruzilhadas, aponta que: “a luta por outras educações, experiências, linguagens e gramáticas é uma luta pela vida (p. 75)” e, desse modo, podemos afirmar que nossa intenção é que busquemos escapar de caminhos retos e seguros 
para apostarmos em outras metodologias e epistemologias, capazes de construir "uma reflexão teórica, bem como uma ação política alicerçadas em uma prática político-epistemológica (GOMES, 2017, p. 140).

Inspirados na proposta de Rufino (2019), apontamos para a emergência dos sujeitos forçadamente silenciados como construtores de possibilidades curriculares diferenciadas que valorizem as suas cosmovisões, seus modos de vida, seus saberes, bem como o reconhecimento dos seus territórios.

É nesse aspecto que a ecologia de saberes promove o diálogo entre os diferentes saberes considerados úteis para o avanço das lutas sociais dos sujeitos quilombolas, de maneira que os saberes e as práticas desses sujeitos dialoguem com o conhecimento científico/escolar. Para isso, à guisa de agenda para o currículo de Biologia na contemporaneidade, é preciso elaborar propostas curriculares capazes de evitar o desperdício tanto das experiências sociais disponíveis, que foram suprimidas e marginalizadas pelo paradigma da racionalidade moderna (sociologia das ausências) quanto das experiências sociais possíveis (sociologia das emergências).

Além disso, ao se tratar de propostas de educação comprometida com a justiça cognitiva/social e com a vida em sua diversidade, a participação e a representação dos sujeitos não deve ser reduzida apenas a pura formalidade; é necessário criar condições reais de participação efetiva das comunidades na elaboração, implementação e avaliação de políticas curriculares específicas em seus territórios e com condições de promoção de sociedades mais justas.

A partir das reflexões sobre o que foi desenvolvido ao longo deste artigo, procuramos também vislumbrar novas frentes de trabalho. É nesse contexto que trazemos para o grupo de pesquisa uma importante contribuição para os estudos que envolvem a decolonialidade e a educação.

A partir de então, inaugura-se uma nova perspectiva que pode atravessar as diferentes linhas de pesquisa do grupo: Currículo, Educação Ambiental e Relações Étnico-Raciais. Os resultados apresentados neste artigo também permitem enveredar por caminhos potentes para fortalecimento da educação, da luta e da resistência quilombola.

Neste processo é imprescindível lançar mão de perspectivas decoloniais, insurgentes e que contestam a perpetuação da colonialidade fundada na racialização, subordinação, exclusão e dominação; assim as pedagogias em contextos de luta e resistência podem viabilizar outras maneiras de ser, de existir e de se relacionar com a natureza, diferentes daquelas impostas pela modernidade eurocêntrica. 
O desfecho dessa pesquisa empreendida foi apenas de iniciar e, portanto, um convite às propostas de pesquisas que dialoguem com as alternativas epistêmicas, as lutas dos sujeitos invisibilizados e com as diversas formas de conhecimento e de vida que emergem da práxis decolonial. É também uma aposta em estudos que possam contribuir, sobretudo, para visibilizar horizontes de alternativas frente à colonialidade do poder/saber/ser e da mãe natureza, que podem ser anunciadas a partir das potencialidades das perspectivas decoloniais e na desconstrução curricular do ensino de Biologia e, desse modo, é possível promover outras epistemologias e metodologias curriculares capazes de avançar nas prescrições curriculares, cientificistas e "buscar outras marcas, da vida cotidiana, das opções tecidas nos acasos e situações que compõem a história de vida dos sujeitos pedagógicos que, em processos reais de interação, dão vida e corpo às propostas curriculares (OLIVEIRA, 2003, p. 69).

Mignolo (2008) nos fala sobre a necessidade de determinada desobediência epistêmica, assim dentro dessa perspectiva, discutir uma Educação Ambiental é trilhar um caminho contrário ao de algumas formas de silenciamento existentes no pensamento hegemônico dominante. O caminhar, nesse sentido, se faz credibilizando outras rotas e confrontando as ordens impostas pelo regime colonial. É caminhar pela discussão da cultura como possibilidade criativa em se pensar/sentir a natureza, e por consequência, a vida em diversidade.

A busca dessa outra racionalidade se constrói no diálogo eu-outro-mundo, e proporciona a compreensão de que a ciência e os outros saberes surgem a partir da percepção do ser/estar no mundo. Entendendo esse movimento como um processo educativo em que também nos modificou ao vivenciar aquela cultura e o que dela sugerimos pensá-la. Outras vozes que conversaram conosco também nos afetou, produziram e desconstruíram nossa visão de currículo e permitiu-nos experimentar e compreender a necessidade, cada vez maior, de (des)construir o currículo do ensino de Biologia, desde a escola à universidade, possibilitando novos enfoques epistemológicos e metodológicos, a partir da promoção de discussão e visibilidade a vozes de resistências que, na maioria das vezes, são subalternizadas.

\section{REFERÊNCIAS}

ARBOLEDA, S. Q. Le han florescido nuevas estrelas al cielo: suficiencias íntimas y clandestinización del pensamiento afrocolombiano. 2011. 403f. Tesis (Doctorado en Estudios Culturales Latinoamericanos), Universidad Andina Simón Bolívar, Santiago de Cali. 2011.

CASTRO-GÓMEZ, S.; GROSFOGUEL, R. El giro decolonial: reflexiones para una diversidad epistémica más allá del capitalismo global. Bogotá: Siglo del Hombre Editores, 2007. 308p. 
BARZANO, M. A.L. Currículo das margens: apontamentos para ser professor de Ciências e Biologia. Educação em Foco, v. 21, p. 105-124, 2016.

DIAS, T. L. S.; EL-HANI, C. N.; ARTEGA, J. S.; BARZANO, M. A. L.; SEPUlVEDA, C. As Contribuições da Exposição Ciência, Raça e Literatura para a Educação das Relações Étnico-Raciais. Revista de Ensino de Biologia da Associação Brasileira de Ensino de Biologia (SBEnBio), v. 7. P. 7226- 7238. Out, 2014.

DIAS, T. L. S.; FERNANDES, Kelly. M.; SÁNCHEZ ARTEAGA, J.; SEPULVEDA, C. Cotas Raciais, genes e Política: uma questão sociocientífica para o ensino de ciências. In: CONRADO, Dália; NUNES NETO, Nei. (Orgs.). Questão Sociocientífica: fundamentos, propostas de ensino e perspectivas para ações sociopolíticas. $1^{\mathrm{a}}$ ed. Salvador: EDUFBA, 2018.

FERNANDES, K. M. Biologia, Educação das Relações Étnico-Raciais e Inversão Epistemológica. Revista Artes de Educar. V. 1. N.2. Pp. 311-323. Jun-Set, 2015.

Biologia decolonial, vida e genocídio da juventude negra. In: PINHEIRO, Barbara Carine Soares; ROSA, Katemari. (Orgs.). Descolonizando saberes: A lei 10.639/2003 no ensino de ciências. São Paulo: Editora Livraria da Física, 2018.

FERREIRA, A. O Currículo em Escolas Quilombolas do Paraná: a possibilidade de um modo de ser, ver e dialogar com o mundo. 2014. 158f. Tese (Doutorado em Educação) - Pontifícia Universidade Católica de São Paulo, 2014.

FERREIRA, M. S. Currículo e cultura: diálogos com as disciplinas escolares Ciências e Biologia. In: MOREIRA. Antonio Flavio; CANDAU, Vera Maria. (Orgs.). Currículos, disciplinas escolares e culturas. Petrópolis: Vozes, 2014. 360p.

FREIRE, P. Pedagogia da Esperança: um reencontro com a pedagogia do oprimido. Rio de Janeiro: Paz e Terra, 1992. $127 \mathrm{p}$.

. Pedagogia do Oprimido. 43 ed. São Paulo: Paz e Terra, 2014. 256p.

GOMES, N. L. Cultura Negra e Educação. Revista Brasileira de Educação. N. 23. Mai-Ago, 2003.

Relações Étnico-raciais, educação e descolonização dos currículos. Currículo sem Fronteiras. V.12,

N.1, pp.98-109, jan/abr, 2012.

O Movimento Negro Educador: saberes construídos nas lutas por emancipação. Petrópolis, RJ: Vozes, 2017. 160p.

GOMES, M. M. Planejamento de ensino, cultura e biologia. In: Danielle Lima-Tavares; Ana Cléa Moreira Ayres; Mariana Lima Vilela; Maria Matos. (Orgs.). Tecendo laços docentes entre Ciência e Culturas. Rio de Janeiro: Editora Prismas, 2016.

HALL, S. A Centralidade da Cultura: notas sobre as revoluções culturais no nosso tempo. Educação e Realidade, Porto Alegre, v.22, n.2, jul/dez, 1997.

LEFF, E. Aventuras da Epistemologia Ambiental: da articulação das ciências ao diálogo de saberes. São Paulo: Cortez Editora, 2012. 132p.

MACÊDO, D. de J. S.. Educação em Comunidades Quilombolas do Território de Identidade do Velho Chico/BA: indagações acerca do diálogo entre as escolas e as comunidades locais. 2015. 216f. Tese (Doutorado em Educação e Contemporaneidade) - Faculdade de Educação, Universidade do Estado da Bahia, Salvador, 2015.

MIGNOLO, W. Desobediências epistêmicas: a opção descolonial e o significado de identidade política. Caderno de Letras da UFF - Dossiê: Literatura, língua e identidade, n. 34, p. 287-324, 2008.

NUNES, G. H. L.. Educação Escolar Quilombola e Lei 10639/03: cartografias territoriais e curriculares. Identidade!, v. 19, n. 2, p. 89-99, Jul/Dez. 2014.

PINHEIRO, B. C. S.; ROSA, K. (Orgs.). Descolonizando saberes: A lei 10.639/2003 no ensino de ciências. São Paulo: Editora Livraria da Física, 2018. 174p.

PINHEIRO, B. C. S. Educação em ciências na Escola Democrática e as Relações Étnico-Raciais. Revista Brasileira de Pesquisa em Educação em Ciências. N. 19, pp.329-344, 2019.

RUFINO, L.. Pedagogia das Encruzilhadas. Rio de Janeiro: Editora Mórula, 2019.

SANTOS, B. de S. Para uma sociologia das ausências e uma sociologia das emergências. Revista Crítica de Ciências Sociais. n. 63, p. 237-280, out. 2002. 
A Universidade no século XXI: para uma reforma democrática e emancipatória da universidade. São Paulo: Cortez, 2005. $2^{\mathrm{a}}$ ed.

(Org). Semear outras soluções: os caminhos da biodiversidade e dos conhecimentos rivais. Rio de Janeiro: Civilização Brasileira, 2005. 501p.

Para além do pensamento abissal. Novos Estudos, v. 79, p. 71-94, nov. 2007.

SANTOS, B. de S.; MENESES, M. P. (Orgs). Epistemologia do Sul. São Paulo: Cortez, 2010. 638p.

SEPÚLVEDA, C. O racismo científico como plataforma para educação das relações étnico-raciais no ensino de ciências. In: CUSTÓDIO, José Francisco; COSTA, David Antonio; FLORES, Cláudia Regina; GRANDO, Regina Célia. (Orgs.). Programa de Pós-Graduação em Educação Científica e Tecnológica (PPGECT): Contribuições para Pesquisa e Ensino. São Paulo: Livraria da Física, 2018, p. 243-270.

SEPUlVEDA, C.; LIMA, D. de B.; RIBEIRO, M. G.; ARTEAGA, J. M. S. Variabilidade humana, raça e o debate sobre cotas raciais em universidades públicas: articulando ensino de genética à educação em direitos humanos. In: TEIXEIRA, Pedro Pinheiro; OLIVEIRA, Roberto Dalmo V. L.; QUEIROZ, Glória R. P. C. (Orgs.). Conteúdos Cordiais: biologia humanizada para uma escola sem mordaça. São Paulo: Editora Livraria da Física, 2019.

TRINDADE, C. B. S. Formação de professores: Saberes Pedagógicos e tradicionais da Etnociência para os anos iniciais em Escolas Quilombolas. 2016. 214f. Tese de doutorado- Programa de Pós-Graduação em Educação em Ciências/UFPA, 2016.

TRISTÃO, M. A Educação Ambiental e o pós-colonialismo. Revista Educação pública. V. 23, n. 53/2, p. 473-489, Mai/Ago. 2014

VERRANGIA, D. O Ensino de Ciências e as Relações Etnicorraciais: alguns desafios para a compreensão de si e do mundo. Anais eletrônicos. VI Encontro Regional de Ensino de Biologia da Regional 2 RJ/ES. CEFET/RJ, 2012.

31, pp.2-27, 2014. Educação Científica e Diversidade Étnico-Racial: o ensino e a pesquisa em foco. Interacções. N.

VERRANGIA, D.; SILVA, P. B. G. Cidadania, relações étnico-raciais e educação: desafios e potencialidades do ensino de Ciências. Educação e Pesquisa. V.36, N.3, pp.705-718, set./dez. 2010.

VERRANGIA, D.; CASTRO, M. A. T. O Ensino de Evolução: contribuições de tradições culturais africanas e afrobrasileiras para a produção de conteúdos cordiais. In: TEIXEIRA, Pedro Pinheiro; OLIVEIRA, Roberto Dalmo V. L.; QUEIROZ, Glória R. P. C. (Orgs.). Conteúdos Cordiais: biologia humanizada para uma escola sem mordaça. São Paulo: Editora Livraria da Física, 2019. 


\section{SABERES DA BIODIVERSIDADE: PERSPECTIVAS DECOLONIAIS NO CURRÍCULO DO ENSINO DE BIOLOGIA}

\section{RESUMO}

$\mathrm{O}$ artigo apresenta um recorte de uma pesquisa de doutorado em diálogo com aquilo que denominamos de "currículo das margens", quando se refere a sujeitos forçadamente invisibilizados que produzem e são produzidos por estes currículos. Pretende-se aqui debruçar na tríade temática: “currículo, relações étnico-raciais e educação ambiental", temas que consideramos importantes na formação do(a) professor(a) de biologia. É neste contexto que, ao abordar sobre os saberes da biodiversidade em uma comunidade quilombola, emergem os saberes nascidos da luta que nos mostram a potência do movimento negro educador e, dessa maneira, uma efetiva contribuição para descolonizar os currículos de ciências/biologia e construir possibilidades para a insurgência de uma pedagogia decolonial.

Palavras-chaves: Currículo; Decolonialidade; Ensino de Biologia

\section{KNOWLEDGE OF BIODIVERSITY: DECOLONIAL PROSPECTS IN THE CURRICULUM OF BIOLOGICAL EDUCATION}

\section{ABSTRACT}

The article presents a clipping of a doctoral research in dialogue with what we call the "margins curriculum", when it refers to forcibly invisible subjects who produce and are produced by these curriculum. The aim here is to focus on the thematic triad: "curriculum, ethno-racial relations and environmental education", themes that we consider important in the formation of the biology teacher. It is in this context that, by addressing the knowledge of biodiversity in a quilombola community, emerged the knowledge born of the struggle that shows us the power of the black educator movement and, thus, an effective contribution to decolonize the science / biology curriculum and build possibilities for the insurgency of a decolonial pedagogy.

Keywords: curriculum; decoloniality; teaching biology4

\section{SABERES SOBRE BIODIVERSIDAD: PESRPECTIVAS DECOLONIALES EN EL CURRICULO PARA LA ENSEÑANZA DE LA BIOLOGÍA}

\section{RESUMEN}

Este artículo presenta una parte de investigación de doctorado en dialogo con aquello que denominamos "currículo de los marginados", refiriéndonos a sujetos invisibilizados forzadamente que producen y son producto de estos currículos. Se pretende profundizaren la triada temática: "currículo, relaciones étnico-raciales y educación ambiental", temáticas que consideramos son importantes en la formación de profesores y profesoras de Biología. Es en ese contexto que, al abordar los saberes en una comunidad Quilombola, los saberes emergen por la lucha del movimiento negro educador mostrándonos su gran potencial y de la misma manera, se obtiene una contribución efectiva para descolonizar los currículos de Ciencias/Biología y construir posibilidades para el surgimiento de una pedagogía decolonial.

Palabras-claves: Plan de estudios; Descolonialidad; Enseñanza de biología

Submetido em Agosto de 2019 Aprovado em Dezembro de 2019 